Institute of $\mathbf{F}_{\text {ood and }} \mathbf{A}$ gricultural $\mathbf{S}_{\text {ciences }}$

\title{
Florida Fresh: Kumquats ${ }^{1}$
}

Jennifer Hillan ${ }^{2}$

You can buy delicious fruits and vegetables at farmers' markets. You can also ask the person who grew it how to eat it! Because the produce is locally grown, it's fresh and costs less than at the supermarket. Enjoy some of your favorites or try something new! To find a farmers' market in your area, call your county Extension office or visit the Florida Department of Agriculture's web site: www.fl-ag.com/farmmkt/city.htm.

\section{History and Facts}

Kumquats are small citrus fruits that are an unusual blend of sweet (skin) and sour (flesh).

You can eat the whole kumquat, but some people don't eat the seeds.

Kumquat means "golden orange."

Dade City, Florida has a Kumquat Festival in January each year.

Just five kumquats have six grams of fiber, almost half of the vitamin $\mathrm{C}$ we need each day, and only 60 calories!

\section{Availability}

December through May

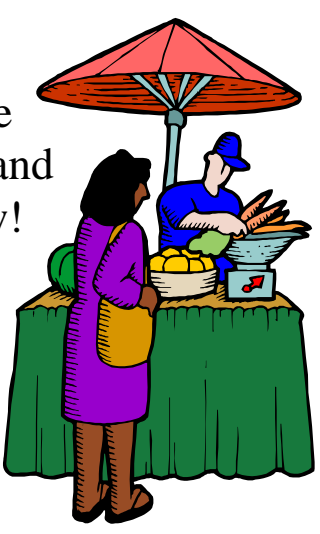

\section{Selection}

Choose kumquats that are firm and bright orange. Avoid any that are soft or shriveled.

\section{Storage}

Refrigerate unwashed kumquats in a plastic bag up to one month.

\section{Uses \& Preparation}

Rinse kumquats before using. Kumquats are often candied or made into marmalades and jellies. They are also colorful additions to many dishes, such as chicken, pork, and fish. Enjoy them whole, like grapes, or add sliced kumquats to sandwiches and salads.

You can also add pureed kumquats to sauces or bread, cake, and muffin mixes. For a fun treat, add kumquat pieces, chopped pineapple, and nuts to flavored gelatin!

1. This document is FCS8675, one of a series of the Department of Family, Youth and Community Sciences, Florida Cooperative Extension Service, Institute of Food and Agricultural Sciences, University of Florida. Publication date: July 2002. Reviewed by Isabel Valentín-Oquendo, MS, RD, LD/N. Please visit the EDIS Web site at http://edis.ifas.ufl.edu

2. Jennifer Hillan, MSH, RD, LD/N, Coordinator, Educational/Training Programs, Department of Family, Youth and Community Sciences, Cooperative Extension Service, Institute of Food and Agricultural Sciences, University of Florida, Gainesville, 32611. 


\section{Nutrient Facts}

* Excellent source of fiber and vitamin $\mathrm{C}$

* Fair source of thiamin, riboflavin, folate, and potassium

\section{What are Organically Grown Foods?}

Organically grown means that a food was grown without synthetic (man-made) pesticides or fertilizers. Natural pesticides and fertilizers were used instead. Organic and non-organic foods are similar in taste and nutritional value. However, organic foods usually cost more.

* Fat and cholesterol free

\section{Kumquat Refrigerator Pie}

Serves 9

1 baked graham cracker pie crust 9"

1 (8oz.) container of fat free whipped topping $2 / 3$ cup pureed kumquat (see directions below)

2 kumquats, rinsed and sliced

1 (14 oz.) can lowfat condensed milk

$1 / 2$ cup lemon juice

Add milk and whipped topping to large bowl. Beat with mixer on high speed until creamy. Add lemon juice and beat until thickened.

Mix in kumquat puree. Pour in pie shell and chill in refrigerator for several hours. Top pie with sliced kumquats and enjoy!

Source: Kumquat Growers, Inc.
Hawaiian Chicken with Kumquats

Serves 6

4 chicken breasts, skin and bones removed, cut in strips

$1 / 4$ cup brown sugar

$1 / 2$ cup ketchup

$1 / 4$ cup vinegar

2 tablespoons cornstarch

1 small green pepper, chopped

1 (8 oz.) can pineapple chunks with juice

8 or 9 kumquats, rinsed and sliced

Place chicken in casserole dish. Mix all remaining ingredients together and pour over chicken. Cover with foil. Bake at $375^{\circ} \mathrm{F}$ for $1-1 / 2$ hours. Serve over rice or noodles.
To blanch kumquats, place in boiling water for about 20 seconds, then quickly place in ice water until completely cooled. Blanching mellows the taste of fresh kumquats.

To puree kumquats, cut in half, remove seeds, and place in blender. Blend on medium speed until smooth. The puree can be frozen up to six months. One quart (about 25 kumquats) makes about 1 cup of puree.

\section{Citrus Salad}

Serves 4

4 cups spinach or other salad greens, rinsed and torn into small pieces

1 grapefruit, rinsed, scrubbed, peeled, and cut into sections 4 kumquats, rinsed, scrubbed, sliced, and seeds removed $1 / 4$ cup sunflower seeds

$1 / 2$ cup reduced fat vinaigrette

Blanch kumquats if desired. Add all ingredients (except sunflower seeds) to large bowl. Toss to coat salad with dressing. Sprinkle with sunflower seeds and serve.

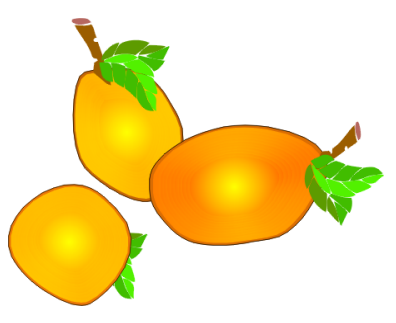

